Original Research Paper

\title{
Impact of Mahatma Gandhi National Rural Employment Guarantee Act Activities on Agriculture as Perceived by Farmers
}

\author{
${ }^{1}$ Thangamalar, S., ${ }^{2 *}$ S. Kalaivani, ${ }^{3}$ S. Palaniswamy and ${ }^{4}$ K.R. Ashok \\ ${ }^{I}$ Department of Agricultural Extension and Rural Sociology, \\ ${ }^{2}$ Department of Sustainable Organic Agriculture, \\ ${ }^{3}$ Directorate of Extension Education, \\ ${ }^{4}$ Department of Agricultural Economics, \\ Tamil Nadu Agricultural University, Coimbatore-641 003, India
}

\author{
Article history \\ Received: 16-02-2015 \\ Revised: 19-06-2015 \\ Accepted: 17-06-2016 \\ Corresponding Author: \\ S. Kalaivani \\ Department of Sustainable \\ Organic Agriculture, Tamil \\ Nadu Agricultural University, \\ Coimbatore-641 003, India \\ Email: velavani@hotmail.com
}

\begin{abstract}
Out of $66.00 \%$ of rural population in India, majority are landless labours depending on the mercy of employment providers for their livelihood. This population is the most vulnerable section to poverty, underemployment, access to development, etc. Therefore the Mahatma Gandhi National Rural Employment Guarantee Act (MGNREGA) has been implemented by the Government of India to improve the living standards of rural poor. This study conducted in Erode district of Tamil Nadu revealed that major impacts of MGNREGA activities on agriculture were in the aspects like soil ecology attributes, water attributes, crop attributes, society attributes, economics attributes, market attributes and labour availability attributes. Majority of the respondents expressed that soil moisture, water percolation, ground water table, area under irrigation, area under cultivation, adoption of crop management technologies, social participation and farm mechanization had increased with improvement in water holding capacity, soil texture, knowledge and skill on crop production due to the activities undertaken under MGNREGA programme.
\end{abstract}

Keywords: MGNREGA, Agriculture, Impact, Farmers Perception

\section{Introduction}

The Mahatma Gandhi National Rural Employment Guarantee Act, 2005 (MGNREGA) has been implemented by the Government of India to improve the living standards of rural poor. The Act was notified in 200 districts in the first phase with effect from February 2nd 2006 and then extended to additional 130 districts in the financial year 20072008. The remaining districts have been notified under the National Rural Employment Guarantee Act with effect from April 1, 2008. This Act is an important step towards the realization of the right to work. It guarantees 100 days of employment in a financial year to any rural household whose adult members are willing to do unskilled manual work. Therefore the present study has been undertaken to analyze whether this act has any impact on agriculture as perceived by farmers.

\section{Materials and Methods}

In Western zone of Tamil Nadu, India, Erode district was purposively selected since it has the highest net area sown. Out of 14 blocks in Erode district, Modakkurichi and Ammapettai blocks had more number of MGNREGA beneficiaries and hence these two blocks were purposively selected for the study. From 23 and 20 village panchayats in Modakkurichi and Ammapettai blocks respectively, three village panchayats were selected from each block based on the number of beneficiaries of MGNREGA. By employing proportionate random sampling method, 20, 16, 16, 24, 23 and 21 respondents were selected from Enjampalli, Attavanai Hanumanpalli, Kagam, Chennampatti, Mathur and Oddapalayam village panchayats and a total of 120 farmers were selected as respondents. The ExpostFacto research design was employed. 
Impact of MGNREGA activities on agriculture has been operationalized as the desirable/undesirable changes that have taken place due to MGNREGA activities on agriculture as perceived by farmers. Various impacts due to MGNREGA activities on agriculture were studied under Soil ecology attributes, Water attributes, Crop attributes, Society attributes, Economics attributes, Market attributes and Labour availability attributes and the farmers were requested to indicate their responses as 'yes' or 'no' for each item. A positive response was assigned with two score while a negative response received one score. The total impact score was obtained by summing up the response of the items. Percentage analysis was done to rank the impact of MGNREGA activities on agriculture.

\section{Findings and Discussion}

The impact of MGNREGA activities on agriculture as perceived by farmers on soil ecology attributes, water attributes, crop attributes, society attributes, economics attributes, market attributes and labour availability attributes is furnished in Table 1 . It could be inferred from Table 1 that an equal per cent of the respondents $(54.17 \%)$ had expressed that the water holding capacity had improved with an increase in water percolation and area under cultivable land respectively. Also a little more than $50.00 \%$ of the respondents equally $(53.33 \%)$ had expressed that the soil moisture had been increased with reduction in frequency of irrigation and improvement in soil texture respectively. This may be due to the implementation of MGNREGA activities like supply channel improvement, micro irrigation, deepening and strengthening of check dams. In the study area cropping intensity was found at high level followed by irrigation intensity and shift in cropping pattern at medium level. This finding is in accordance with the findings of Tiwari et al., (2011) who reported that water percolation had increased with an improvement in soil fertility that leads to improved land productivity.

Also it could be observed from Table 1 that more than $50.00 \%$ of the respondents had expressed that MGNREGA activities had increased the ground water table $(53.33 \%)$, area under irrigation $(55.83 \%)$ and enabled them to shift to irrigated crops $(56.67 \%)$. This finding is in line with the findings of UNDP (2010) who reported that irrigated land had increased due to MGNREGA activities. Tiwari et al. (2011) also reported that level of ground water table had increased.

From the results it is also evident that a little more than two-third of the respondents (68.33\%) had expressed that there was change in the cultivation of number of crops per year due to MGNREGA activities. This may be due to the shift in cropping pattern by the farmers. More than $50.00 \%$ of the respondents had revealed that the MGNREGA activities had enabled them to change the cropping pattern $(50.83 \%)$, cropping sequence $(53.33 \%)$, to adopt the recommended crop management technologies (53.33\%) and improvement in knowledge and skills on crop production (61.67\%). Only less than forty per cent $(38.33 \%)$ of the respondents had expressed that they were able to cultivate hybrid crops.

It could be observed from the findings that majority of the respondents had expressed positive response towards the society related attributes viz., developing cooperation among neighbouring farmers (85.00\%), increasing the social recognition $(76.67 \%)$, increasing social contacts $(75.00 \%)$ and increasing participation in the social organization $(74.17 \%)$ since the respondents had medium level social participation.

It could be viewed from the results that more than half of the respondents had expressed that their savings/deposits had increased $(55.00 \%)$ followed by purchase of farm animals (51.67\%). Also more than forty per cent of the respondents $(43.33 \%)$ had revealed that they were able to repay the debts. Nearly thirty per cent $(29.17 \%)$ of the respondents had reported that they had created additional employment opportunities followed by 15.00 and $14.17 \%$ who had purchased additional crop land and farm implements/machineries respectively. This may be due to the fact that $69.17 \%$ of the respondents had possessed farm size ranging from 1.00 to 5.00 acres only and found as marginal to small farmers.

The results also revealed that more than forty per cent of the respondents $(43.33 \%)$ had expressed that they had opportunity to use market throughout the year followed by $41.67 \%$ who had reported that their marketing skills were increased. A little above four-fifth of the respondents $(85.83 \%)$ expressed that labour availability for crop production had reduced with an increase in the wage rate of labourers $(85.00 \%)$ and farm mechanization (75.00\%). Hence during peak seasons of agriculture farm mechanization had increased.

\section{Constraints Faced by the Farmers in Agriculture Due to MGNREGA Activities}

The distribution of respondents according to their constraints faced in agriculture due to MGNREGA activities furnished in Table 2 revealed that increase in agricultural wage rate and non availability of labourers during peak season were the major constraints expressed by cent per cent of respondents. This finding is similar with the findings of Joseph et al. (2009; Sharma et al., 2011; Channaveer et al., 2011; Gulati and Jena, 2012) who had also expressed that the increase in agricultural wage rate and non availability of labourers were the constraints due to MGNREGA activities. 
Table 1. Distribution of respondents according to the attributes of impact $(n=120)$

\begin{tabular}{|c|c|c|c|c|c|c|}
\hline \multirow{3}{*}{ Attributes of Impact } & \multicolumn{4}{|c|}{ Responses } & & \\
\hline & \multicolumn{2}{|l|}{ Yes } & \multicolumn{2}{|l|}{ No } & \multicolumn{2}{|c|}{ Total } \\
\hline & No. & $\%$ & No. & $\%$ & No. & $\%$ \\
\hline \multicolumn{7}{|l|}{ Soil ecology attributes } \\
\hline $\begin{array}{l}\text { Increases soil moisture retention and reduces the } \\
\text { frequency of irrigation }\end{array}$ & 64 & 53.33 & 56 & 46.67 & 120 & 100.00 \\
\hline Improves soil texture & 64 & 53.33 & 56 & 46.67 & 120 & 100.00 \\
\hline Improves water holding capacity & 65 & 54.17 & 55 & 45.83 & 120 & 100.00 \\
\hline Increases water percolation & 65 & 54.17 & 55 & 45.83 & 120 & 100.00 \\
\hline Increases area under cultivable land & 65 & 54.17 & 55 & 45.83 & 120 & 100.00 \\
\hline \multicolumn{7}{|l|}{ Water attributes } \\
\hline Increases ground water table & 64 & 53.33 & 56 & 46.67 & 120 & 100.00 \\
\hline Increases area under irrigation & 67 & 55.83 & 53 & 44.17 & 120 & 100.00 \\
\hline Enables to shift to irrigated crops & 68 & 56.67 & 52 & 43.33 & 120 & 100.00 \\
\hline \multicolumn{7}{|l|}{ Crop attributes } \\
\hline Cultivation of no. of crops changed in a year & 82 & 68.33 & 38 & 31.67 & 120 & 100.00 \\
\hline Enables to change in cropping pattern & 61 & 50.83 & 59 & 49.17 & 120 & 100.00 \\
\hline Enables to change in cropping sequence & 64 & 53.33 & 56 & 46.67 & 120 & 100.00 \\
\hline \multicolumn{7}{|l|}{ Helps to adopt the recommended crop management } \\
\hline technologies & 64 & 53.33 & 56 & 46.67 & 120 & 100.00 \\
\hline Enables to cultivate hybrid crops & 46 & 38.33 & 74 & 61.67 & 120 & 100.00 \\
\hline \multicolumn{7}{|l|}{ Society attributes } \\
\hline Increases the social recognition & 92 & 76.67 & 28 & 23.33 & 120 & 100.00 \\
\hline Develops co-operation among neighbouring farmers & 102 & 85.00 & 18 & 15.00 & 120 & 100.00 \\
\hline Increases participation in the social organization & 89 & 74.17 & 31 & 25.83 & 120 & 100.00 \\
\hline Increases social contacts & 90 & 75.00 & 30 & 25.00 & 120 & 100.00 \\
\hline \multicolumn{7}{|l|}{ Economics attributes } \\
\hline Enables to purchase additional crop land & 18 & 15.00 & 102 & 85.00 & 120 & 100.00 \\
\hline Increases the purchase of farm implements/machineries & 17 & 14.17 & 103 & 85.83 & 120 & 100.00 \\
\hline Increases the purchase of farm animals & 62 & 51.67 & 58 & 48.33 & 120 & 100.00 \\
\hline Enables to repay the debts & 52 & 43.33 & 68 & 56.67 & 120 & 100.00 \\
\hline Increases the savings/deposits & 66 & 55.00 & 54 & 45.00 & 120 & 100.00 \\
\hline Creates additional employment opportunities & 35 & 29.17 & 85 & 70.83 & 120 & 100.00 \\
\hline \multicolumn{7}{|l|}{ Market attributes } \\
\hline $\begin{array}{l}\text { Increase the use and frequency of new media tools like } \\
\text { internet (Agritech portal) and mobile phones (DEMIC } \\
\text { and DMI) to know the market information }\end{array}$ & 30 & 25.00 & 90 & 75.00 & 120 & 100.00 \\
\hline Enhances marketing skills & 50 & 41.67 & 70 & 58.33 & 120 & 100.00 \\
\hline Provides an opportunity to use market throughout the year & 52 & 43.33 & 68 & 56.67 & 120 & 100.00 \\
\hline
\end{tabular}

Table 2. Distribution of respondents according to their constraints faced in agriculture due to MGNREGA activities ( $\mathrm{n}=120)$

\begin{tabular}{llr}
\hline Constraints & Number & $\%$ \\
\hline Increase in agricultural wage rate & 120 & 100.00 \\
Non availability of labourers in peak season & 120 & 100.00 \\
Unable to do hand weeding and increase in the use of weedicides & 75 & 62.50 \\
Unable to practice mechanical pest control methods and increase in the use of pesticides & 75 & 62.50 \\
Increase in cost of cultivation & 85 & 70.83 \\
\hline
\end{tabular}

*Multiple responses obtained

Table 3. Distribution of respondents according to the suggestions offered to overcome the constraints in agriculture due to MGNREGA activities $(\mathrm{n}=120)$

\begin{tabular}{lr}
\hline Suggestions & Number \\
\hline Implementation of MGNREGA programme in lean season & 120 \\
Allotment of MGNREGA workers for agricultural work in peak season & 96 \\
Willingness of farmers to share wage rate on 50:50 ratio between the government and farmers & 80.00 \\
Creation of new ponds and water harvesting structures & 70.83 \\
\hline
\end{tabular}

\footnotetext{
*Multiple responses obtained
} 
More than $70.00 \%(70.83 \%)$ of the respondents had reported the increase in cost of cultivation as a constraint due to the MGNREGA programme. Also it could be observed that equal distribution of $62.50 \%$ of the respondents had revealed that they were unable to do hand weeding and hence increased the usage of weedicides and unable to practice mechanical pest control methods and increased the usage of pesticides respectively.

Suggestions Offered by the Farmers to Overcome the Constraints in Agriculture Due to MGNREGA Activities

The distribution of respondents according to their suggestions offered to overcome the constraints in agriculture due to MGNREGA activities is presented in Table 3 . It could be inferred from Table 3 that per cent of the respondents had suggested to implement the MGNREGA programme in lean season so that it may not affect the agricultural activities. This finding is in accordance with the finding of Venkataraman et al. (2011) who also suggested that the MGNREGA activities may be reorganized during the lean agricultural season (February to May) so as to avoid the intersectoral competition for the labour force.

Also it could be observed from Table 3 that 80.00 , 70.83 and $56.67 \%$ of the respondents had suggested allotting MGNREGA workers for agricultural work during peak season, their willingness to share wage rate on 50:50 ratio between the government and farmers and creation of new ponds and water harvesting structures respectively.

\section{Conclusion}

The overall impact in soil ecology attributes, water attributes, crop attributes, society attributes, economics attributes, market attributes and labour availability attributes were ranging from 40.00 to $80.00 \%$ due to MGNREGA activities on agriculture. This was due to the MGNREGA activities like supply channel improvement, micro irrigation, deepening and strengthening of check dams. So, government may concentrate on providing more water related works like creation of new ponds and water harvesting structures to MGNREGA workers. The study also indicated that MGNREGA work should be implemented in lean season. Therefore, agricultural works will not be affected and beneficiaries of MGNREGA workers will get income from both farm and nonfarm activities.

\section{Acknowledgement}

The authors thank the Tamil Nadu Agricultural University, Coimbatore, India for providing facilities to carry out this work.

\section{Funding Information}

The authors have no funding to report.

\section{Authors Contribution}

All authors contributed equally in this research work.

\section{Ethics}

This article is original and not published elsewhere. Corresponding author confirms that all authors have approved the manuscript and there are no ethical issues in publication of the manuscript.

\section{References}

Channaveer, H. Lokesha, L.B. Hugar, J.B. Deshmanya and S.B. Goudappa, 2011. Impact of MGNREGA on Input-use pattern, labour productivity and returns of selected crops in Gulbarga district, Karnataka. Agric. Econ. Res. Rev., 24: 517-523.

Gulati, A. and A.K. Jena, 2012. Rural prosperity and no mirage. Economic Times.

Joseph, J., K.T. George and S.K. Dey, 2009. Family labour shortage under rubber block plantation scheme in Tripura. Rubber Board Bull., 29: 12-18.

Sharma, G., J. Joby, G.K. Tharian and S.K. Dey, 2011. Impact of mahatma gandhi national rural employment guarantee act on rubber block plantation scheme in Tripura. Agric. Econ. Res. Rev., 24: 525-530.

Tiwari, R., H.I. Somashekhar, V.R.R. Parama, I.K. Murthy and M.S.M. Kumar et al., 2011. MGNREGA for environmental service enhancement and vulnerability reduction: Rapid appraisal in Chitradurga district, Karnataka. Econ. Political Weekly, 46: 39-47.

UNDP, 2010. Impact assessment of MGNREGA's activities for ecological and economic security. Report Submitted to the Ministry of Rural Development/UNDP, Bhopal.

Venkataraman, R., V. Ravichandran and V. Banumathy, 2011. Performance of MGNERG programme in keerapalayam block in Cuddalore district of Tamil Nadu. Agric. Econ. Res. Rev., 24: 546-546. 